\title{
Effect of cationic monomer structure on the aggregation behavior of amphoteric acrylic polymer around isoelectric point
}

\author{
Qijun $\mathrm{Li}^{1}$, Yudan $\mathrm{Yi}^{2}$, Ya-nan Wang ${ }^{1,2^{*}} \mathbb{D}$, Jing $\mathrm{Li}^{3}$ and Bi Shi ${ }^{1,2}$
}

\begin{abstract}
Amphoteric polymer can be used as retanning agent in leather manufacture. It is particularly useful in chrome-free tanning systems since it can regulate the charge properties of chrome-free leather and enhance the fixation of anionic post-tanning chemicals in leather. However, the aggregation and precipitation of amphoteric polymer retanning agents around the isoelectric point (pl) hinder their wide application. Herein, we synthesized five amphoteric acrylic polymers (AAPs) by free radical copolymerization with acrylic acid and five different cationic acrylic monomers. The effect of cationic monomer structure on the aggregation behavior of AAPs was investigated. The aggregation of AAPs in aqueous solution showed $\mathrm{pH}$ and concentration dependence. Light scattering analysis showed that Poly (AA-co-MAPTAC) and Poly (AA-co-DMAPMA) were in the shape of coiled linear flexible chains with small particle size $\left(R_{g} 7.6 \mathrm{~nm}\right.$ and $14.8 \mathrm{~nm}$, respectively) near the pl. However, Poly (AA-co-DAC), Poly (AA-co-DMC) and Poly (AA-coDMAEMA) were in the shape of hollow spheres and exhibited serious aggregation. Quantum chemical calculations suggested that the amide groups in the cationic monomers MAPTAC and DMAPMA enhanced the nucleophilicity of AAPs. Thus the corresponding AAPs could carry a large number of cationic charges to slow their aggregation when the $\mathrm{pH}$ just climbed over the pl. The results are expected to provide theoretical reference for the synthesis and widespread application of AAPs.
\end{abstract}

Keywords: Amphoteric acrylic polymer, Isoelectric point, Aggregation behavior, Cationic monomer, Retanning

\section{Introduction}

Chrome-free tanning technology can eliminate the emission of chrome-containing wastewaters and solid wastes from the source, and play an important role in promoting the sustainable development of the leather industry [13]. In recent years, significant progress has been achieved in the tanning technology of chrome-free leather manufacturing system $[4,5]$. However, the conventional post-tanning chemicals and technologies are not well compatible with this system. In particular, the isoelectric point (pI) of chrome-free tanned semi-finished leather

\footnotetext{
*Correspondence: wangyanan@scu.edu.cn

${ }^{1}$ Key Laboratory of Leather Chemistry and Engineering (Sichuan

University), Ministry of Education, Chengdu 610065, China

Full list of author information is available at the end of the article
}

(wet white) is significantly different from that of chrome tanned one [6], which leads to poor fixation of conventional anionic post-tanning chemicals in the chrome-free leather [7]. It has been reported that amphoteric polymer retanning agents with appropriate $\mathrm{pI}$ could adjust the charge properties of wet white leather to improve penetration and fixation of post-tanning chemicals, so as to result in satisfactory physical and organoleptic properties of chrome-free leathers [8-10].

According to structures, amphoteric polymer retanning agents are classified into amphoteric acrylic polymer [11-13], amphoteric polyurethane [14, 15], amphoteric syntan [16], etc. Among them, amphoteric acrylic polymer (AAP), which is a linear polymer synthesized by free radical co-polymerization of anionic acrylic monomers and cationic acrylic monomers, is 
the most widely used type. During the retanning process, the $\mathrm{pH}$ of float drops from 5-6 at the beginning to below 4 at the end. This $\mathrm{pH}$ change usually passes through the pI of AAP. When the $\mathrm{pH}$ of float is close to the $\mathrm{pI}$ of AAP, the cationic and anionic groups on the AAP chains will strongly interact with each other through electrostatic force. This may lead to serious aggregation and precipitation of AAP [17], and then cause the uneven penetration and distribution of AAP in the leather.

In order to achieve wide application of AAP in chrome-free tanning system, it is necessary to develop new products with a certain dispersion stability near the pI. The selection of anionic/cationic acrylic monomers is one of the crucial issues. The protonation ability of AAPs at a certain $\mathrm{pH}$ differ from one another due to their different monomer structures, which will affect the strength of the intra-/inter-chain electrostatic interactions, as well as the spatial structure and aggregation state of AAPs [18-20]. In this study, five cationic acrylic monomers (Fig. 1) were selected to synthesize AAPs by free radical copolymerization with acrylic acid, respectively. The structures of the AAPs were characterized by Fourier transform infrared (FT-IR) spectroscopy, nuclear magnetic resonance (NMR) spectroscopy and size exclusion chromatography (SEC). The effect of chemical structure of cationic monomers on the properties of AAPs, especially the aggregation behavior near the $\mathrm{pI}$, was investigated by dynamic/static light scattering (DLS/SLS), diffusing wave spectroscopy (DWS), zeta potential and quantum chemical calculations. We hope to select suitable cationic monomers and guide the preparation of amphoteric polymer retanning agents for chrome-free tanning system.

\section{Experimental}

\subsection{Materials}

Acryloyloxyethyl trimethyl ammonium chloride (DAC, $80 \mathrm{wt} \%$ ), 3-(methacryloylaminopropyl) trimethylammonium chloride (MAPTAC, $50 \mathrm{wt} \%$ ), dimethylaminoethyl methacrylate (DMAEMA, $99.5 \mathrm{wt} \%$ ), and dimethylaminopropyl methacrylamide (DMAPMA, $98.5 \mathrm{wt} \%$ ) were purchased from Feymer Technology Co., Ltd. (Jiangsu, China). Methacryloxyethyl trimethyl ammonium chloride (DMC, $75 \mathrm{wt} \%$ ) and Poly (diallyldimethylammonium chloride) (PDDA, $20 \mathrm{wt} \%$ ) were purchased from Aladdin Reagent Co., Ltd. (Shanghai, China). Acrylic acid (AA, $99 \mathrm{wt} \%$ ) was provided by Sichuan Decision New Material Technology Co., Ltd. (Sichuan, China). Ammonium persulfate and sodium bisulfite were purchased from Chengdu Kelong Chemical Reagent Co., Ltd. (Sichuan, China). Poly (vinyl sulfate) potassium (PVSK, $0.0025 \mathrm{~mol} / \mathrm{L}$ ) was purchased from Wako Pure Chemical Industries, Ltd. (Japan). PEO standards were purchased from Agilent Technologies Co., Ltd. (USA). PEG standards were purchased from Tosoh Corporation (Japan).

\subsection{Preparation of AAPs}

Acrylic acid $(0.4 \mathrm{~mol})$ and a certain amount of deionized water were first added to a four-necked round-bottom flask $(500 \mathrm{~mL})$ equipped with a thermometer, a stirrer and two constant pressure funnels, and then sodium hydroxide solution (32 wt\%) was slowly added dropwise under stirring to control the neutralization degree (the stoichiometric proportion of the neutralized acrylic acid) to $95 \%$. Then $0.14 \mathrm{~mol}$ cationic monomer and a chain transfer agent $(0.1 \%-0.3 \%$ of the weight of blend monomer) were added. The temperature was kept below $40{ }^{\circ} \mathrm{C}$ by partially immersing the flask in a cold-water bath.<smiles>C=CC(=O)OCC[N+](C)(C)C</smiles>

Acryloyloxyethyl trimethyl ammonium chloride (DAC)<smiles>C=C(C)C(=O)NCCCN(C)C</smiles>

Dimethylaminopropyl methacrylamide (DMAPMA)<smiles>C=C(C)C(=O)OCC[N+](C)(C)C</smiles>
Methacryloxyethyl trimethyl
ammonium chloride (DMC)<smiles>C=C(C)C(=O)OCCN(C)C</smiles>

Dimethylaminoethyl methacrylate (DMAEMA)

Fig. 1 Chemical structure of the cationic monomers 
The theoretical solid content of the AAPs was controlled to $35 \%$ by adding deionized water into another empty reactor, and then the reactor was heated to $85^{\circ} \mathrm{C}$ in an oil bath. Ammonium persulfate (1.5\% of the weight of blend monomer) solution and the blend monomer solution were simultaneously added through constant flow pumps in $90 \mathrm{~min}$. The temperature was kept constant for 120 min after feeding. Sodium bisulfite (1.5\% of the weight of blend monomer) solution was added to remove the residual initiator. AAPs were obtained after cooling to room temperature.

\subsection{FT-IR analysis}

AAPs were lyophilized, ground to solid powder, and pressed using the $\mathrm{KBr}$ disk method. The FT-IR spectra of AAPs were recorded in the range from 400 to $4000 \mathrm{~cm}^{-1}$ using FT-IR spectrometer (Nicolet IS10, Thermo Fisher) with a resolution of $4 \mathrm{~cm}^{-1}$ and 64 scans.

\section{$2.4{ }^{13} \mathrm{C}$ NMR analysis}

The lyophilized AAP was dissolved in $\mathrm{D}_{2} \mathrm{O}$ to prepare a $200 \mathrm{mg} / \mathrm{mL}$ sample solution. The ${ }^{13} \mathrm{C}$ NMR spectra of AAPs were recorded on a NMR spectrometer (Avance II $400 \mathrm{MHz}$, Bruker).

\subsection{SEC analysis}

Weight-average molecular weight $\left(M_{w}\right)$ and numberaverage weight $\left(M_{n}\right)$ of AAPs were determined by SEC. Fifty $\mu \mathrm{L}$ of AAP solution $(5 \mathrm{mg} / \mathrm{mL})$ was filtrated through a membrane of $0.22 \mu \mathrm{m}$ pore size. Then it was injected into the high-performance liquid chromatography (1260 Infinity II, Agilent) equipped with a TSK-gel GMPWXL column $\left(7.8 \mathrm{~mm} \times 300 \mathrm{~mm}\right.$, Tosoh) and eluted by $\mathrm{NaNO}_{3}$ $(0.1 \mathrm{~mol} / \mathrm{L})$ at a flow rate of $0.6 \mathrm{~mL} / \mathrm{min}$ under $30{ }^{\circ} \mathrm{C}$. Molecular weight of the AAPs was calculated using The standard curve established by PEG and PEO standards.

\subsection{Isoelectric point (pl) and particle size determination}

The zeta potentials of AAP aqueous solution $(5 \mathrm{mg} / \mathrm{mL})$ in the $\mathrm{pH}$ range of 2.0-8.0 were determined using a particle size \& zeta potential analyzer (NanoBrook Omni, Brookhaven). Each sample was tested 5 times at $25{ }^{\circ} \mathrm{C}$ to obtain the average. The $\mathrm{pH}$ value at the zero point of zeta potential was recorded as the $\mathrm{pI}$ of the AAP. The hydrodynamic diameter $\left(D_{h}\right)$ and particle size distribution of AAP aqueous solution at different concentrations $(0.5-5 \mathrm{mg} / \mathrm{mL})$ or different $\mathrm{pH}(2.0-8.0)$ were also determined by this instrument. All the measurements were carried out at a scattering angle of $90^{\circ}$ with an equilibration time of $3 \mathrm{~min}$ at $25^{\circ} \mathrm{C}$.

\subsection{Turbidity measurement}

The turbidity values of AAP aqueous solution (3 wt\%) in the $\mathrm{pH}$ range of 2-8 were determined by a scattered light turbidimeter (WGZ-3, Xinrui). The test limit of this instrument is 1000 NTU.

\subsection{DLS/SLS analysis}

A series of AAP solutions $(1.4-5.3 \mathrm{mg} / \mathrm{mL})$ were prepared using citric acid-sodium citrate buffer $(0.1 \mathrm{~mol} / \mathrm{L})$ of $\mathrm{pH} 4$ as solvent. After filtration through membrane of $1.0 \mu \mathrm{m}$ pore size, the samples were used for DLS/ SLS measurements by a compact goniometer system (CGS-3, ALV) equipped with a He-Ne laser (wavelength $\lambda=632.8 \mathrm{~nm}, 22 \mathrm{~mW}$ ) at $25{ }^{\circ} \mathrm{C}$. DLS measurement was carried out at a scattering angle of $90^{\circ}$, and the intensity correlation function $\mathrm{g}^{2}(\mathrm{t})$ was analyzed using the Cumulant method to obtain the hydrodynamic radius $\left(\mathrm{R}_{\mathrm{h}}\right)$ of the sample. SLS measurement was carried out at scattering angles from $40^{\circ}$ to $140^{\circ}$ with a step of $5^{\circ}$. The data were evaluated using Zimm plot extrapolation by ALVStat software to yield the radius of gyration $\left(R_{\mathrm{g}}\right)$ and second virial coefficient $\left(\mathrm{A}_{2}\right)$ of the sample.

\subsection{DWS analysis}

The intensity autocorrelation function of AAP aqueous solutions $(5 \mathrm{mg} / \mathrm{mL})$ at the $\mathrm{pI}$ was determined by DWS (DWS RheoLab, LS Instrument) with a laser at the wavelength of $685 \mathrm{~nm}(40 \mathrm{~mW})$ using transmission mode. A cuvette with a thickness of $10 \mathrm{~mm}$ was used. The temperature was $25^{\circ} \mathrm{C}$, and the test time was $3 \mathrm{~min}$.

\subsection{Cationic degree determination}

Cationic degree of AAPs, defined as the amount of substance of positive charge in the polymer per unit mass at a certain $\mathrm{pH}$, was determined by the colloidal titration method $[21,22]$. The $\mathrm{pH}$ of AAP solution $(50 \mathrm{~mL}, 0.1 \mathrm{~g} / \mathrm{L})$ was adjusted to 2, 4, 6 and pI, and $15 \mathrm{~mL}$ PVSK solution $(0.0025 \mathrm{~mol} / \mathrm{L})$ was added. After stirring for $30 \mathrm{~min}$, toluidine blue indicator was added. The blend was titrated with PDDA standard solution to the end point where the color changed from purple-red to blue, and precipitation was formed. Moreover, $50 \mathrm{~mL}$ deionized water was used for a blank determination. Each sample was tested in duplicate to obtain the average. The cationic degree was calculated as follows:

$$
\text { Cationic degree }(\mathrm{mmol} / \mathrm{g})=\frac{f \times\left(V_{1}-V_{2}\right)}{m}
$$

where $f$ is the concentration of PDDA standard solution $(0.005 \mathrm{~mol} / \mathrm{L}), V_{1}$ is the volume of PDDA solution used for blank titration (mL), $V_{2}$ is the volume of PDDA solution used for sample titration $(\mathrm{mL})$, and $m$ is the weight of the sample (g). 


\subsection{Quantum chemical calculations}

The molecular models of AAPs with a polymerization degree of 3 (acrylic acid-cationic monomer-acrylic acid) were constructed. The density functional theory (DFT) method with B3LYP hybrid functional was used for computation, and the Gaussian basis set 6-31G(d) was chosen. All calculations were performed using Gaussian 09W program [23]. The optimized structures and harmonic vibrational properties of the models were obtained. The chemical potential $\mu$ and chemical hardness $\eta$ were calculated from the highest occupied molecular orbital (HOMO) energy $\varepsilon_{H}$ and the lowest unoccupied molecular orbital (LUMO) energy $\varepsilon_{L}$, and then the electrophilic factor $\omega$ was calculated using the following equations [24, 25]:

$$
\begin{aligned}
& \mu=\frac{\varepsilon_{H}+\varepsilon_{L}}{2} \\
& \eta=\varepsilon_{H}-\varepsilon_{L} \\
& \omega=\frac{\mu^{2}}{2 \eta}
\end{aligned}
$$

\section{Results and discussion}

\subsection{Structural characterization of AAPs}

The FT-IR spectra of AAPs are shown in Additional file 1: Fig. S1. The ${ }^{13} \mathrm{C}-\mathrm{NMR}$ spectra of AAPs are shown in Additional file 1: Fig. S2. The chemical shifts of secondary carbon atoms $\left(\mathrm{C}_{\mathrm{j}}\right)$, tertiary carbon atoms $\left(\mathrm{C}_{\mathrm{k}}\right)$ and quaternary carbon atoms $\left(\mathrm{C}_{1}\right)$ on the polymer backbone were observed at 35-38 ppm, 42-43 ppm and 44-45 ppm, respectively. These results demonstrated that AAPs were successfully synthesized [26]. Among the cationic monomers used for polymerization, DMC, DAC, and DMAEMA are acryloxy-alkyl cationic monomers with ester group in the side chain. MAPTAC and DMAPMA are acrylamide-alkyl cationic monomers with amide group in the side chain. Moreover, DMC, DAC, and MAPTAC are monomers with quaternary ammonium group. DMAPMA and DMAEMA are monomers with tertiary amine group. The structural features of the cationic monomers can also be characterized by FT-IR and ${ }^{13}$ C-NMR spectra of AAPs (Additional file 1: Figs. S1, S2).

\subsection{Molecular weight and pl of AAPs}

Table 1 shows the $M_{w}, M_{n}$, polydispersity $\left(M_{w} / M_{n}\right)$ and pI of AAPs. The molecular weights of AAPs were close $\left(\mathrm{M}_{\mathrm{w}}\right.$ between $\left.64,000-72,000\right)$ by adjusting the amount of chain transfer agent during polymerization to better investigate the effect of cationic monomer structure on the properties of AAPs. The pIs of AAPs were between
Table 1 Molecular weight and pl of AAPs

\begin{tabular}{lllll}
\hline Sample & $\boldsymbol{M}_{\boldsymbol{w}}(\mathbf{g} / \mathbf{m o l})$ & $\boldsymbol{M}_{\boldsymbol{n}} \mathbf{( g / \mathbf { m o l } )}$ & $\boldsymbol{M}_{\boldsymbol{w}} \boldsymbol{M}_{\boldsymbol{n}}$ & $\mathbf{p l}$ \\
\hline Poly (AA-co-DAC) & 71,081 & 15,078 & 4.71 & 4.15 \\
Poly (AA-CO-DMC) & 65,451 & 30,483 & 2.15 & 4.27 \\
Poly (AA-CO-MAPTAC) & 62,734 & 13,396 & 4.68 & 4.33 \\
Poly (AA-co-DMAPMA) & 69,321 & 15,463 & 4.48 & 4.07 \\
Poly (AA-co-DMAEMA) & 64,491 & 29,555 & 2.18 & 3.95 \\
\hline
\end{tabular}

3.9 and 4.4. Poly (AA-co-DMAPMA) and Poly (AA-coDMAEMA) with tertiary amine group exhibited slightly lower $\mathrm{pI}$ than the polymers with quaternary ammonium group. Moreover, among the AAPs with quaternary ammonium group, the pI of Poly (AA-co-MAPTAC) containing amide in the cationic monomer was slightly higher than those of Poly (AA-co-DAC) and Poly (AAco-DMC) containing ester.

\subsection{Effect of $\mathrm{pH}$ on the aggregation behavior of AAPs}

The $\mathrm{pH}$ dependence of the turbidity and the particle size distribution of AAP solutions are shown in Fig. 2. Each sample remained clear with very low turbidity at $\mathrm{pH} 2$, 6 and 8 . The $D_{h}$ was as small as $10-20 \mathrm{~nm}$. However, $D_{h}$ and turbidity increased remarkably, and intense aggregation and even precipitation occurred when the $\mathrm{pH}$ was around 4, that is near the pI of AAPs (see Table 1). These results can be attributed to the classical $\mathrm{pH}$-responsive property of amphoteric polyelectrolyte [27, 28]. When the $\mathrm{pH}$ was away from the $\mathrm{pI}$, the polymer carried a large number of positive or negative net charges because of the protonation of cationic monomers or the dissociation of acrylic monomers. The polymer chains were unfolded and dispersed far from each other in aqueous media due to their electrostatic repulsion. When the $\mathrm{pH}$ was at the $\mathrm{pI}$ of AAPs, the polymer with zero net charge showed strong aggregation, possibly because the electrostatic attraction between/within the polymer chains was greater than the repulsion $[29,30]$.

Although the molecular weights of various AAPs were similar, Poly (AA-co-MAPTAC) and Poly (AA-coDMAPMA) with amide in the cationic monomers had smaller $D_{h}$ at the pI (800-1100 nm), whereas the other three AAPs with ester in the cationic monomers $\left(D_{h}\right.$ around $2000 \mathrm{~nm}$ ) showed drastic aggregation and even precipitated at the pI. This phenomenon may be attributed to the different protonation ability of cationic monomers in different AAPs near the pI, which resulted in different strength of electrostatic interaction between polymer chains [31, 32]. Further analysis will be presented in the following sections. 

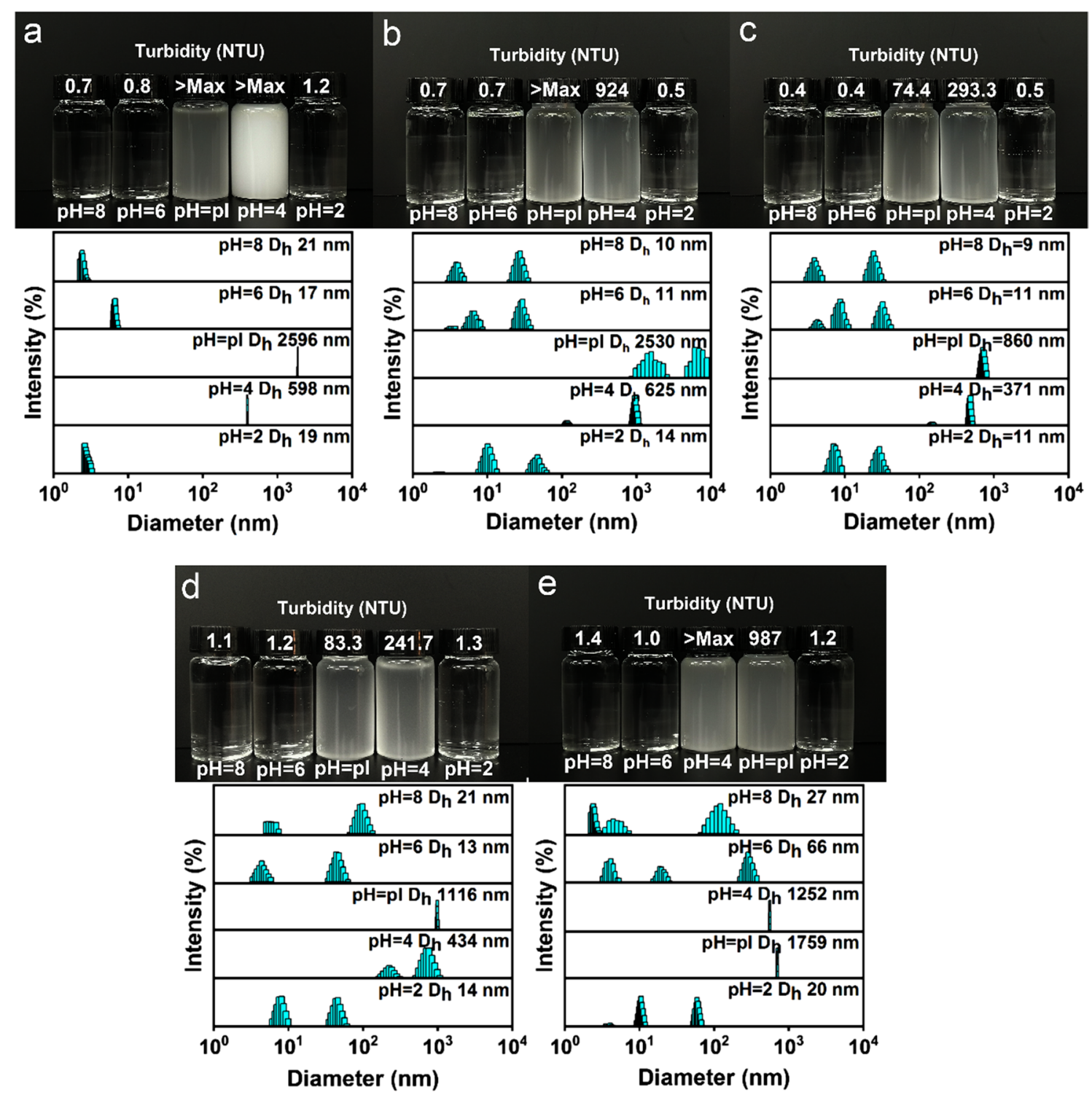

Fig. 2 Particle size distribution and turbidity of Poly (AA-co-DAC) (a), Poly (AA-co-DMC) (b), Poly (AA-co-MAPTAC) (c), Poly (AA-co-DMAPMA) (d) and Poly (AA-CO-DMAEMA) (e) under different $\mathrm{pH}$ conditions

\subsection{Effect of concentration on the aggregation behavior of AAPs}

The aggregation behavior of AAPs showed concentration dependence in addition to $\mathrm{pH}$ dependence. As seen from Fig. 3, the $D_{h}$ of AAPs at the pI increased with increased concentration because of the enhanced interactions between the polymer chains [33]. Similar to the $\mathrm{pH}$ dependence, AAPs with varied cationic monomer structures showed significant differences in the aggregation state at pI. When the concentration of AAP solution was $0.5 \mathrm{~g} / \mathrm{L}$, Poly (AA-co-MAPTAC) was the most stable with the smallest $D_{h}(42 \mathrm{~nm}$, Fig. 3c). When the concentration increased to $5.0 \mathrm{~g} / \mathrm{L}$, the $\mathrm{D}_{\mathrm{h}}$ of Poly (AA-co-MAPTAC) and Poly (AA-co-DMAPMA) that contained amide in the cationic monomers were around $1200 \mathrm{~nm}$ (Fig. 3c, d). The other AAPs containing ester in the cationic monomers exhibited serious aggregation at $\mathrm{pI}$, and their $\mathrm{D}_{\mathrm{h}}$ rose to more than $2000 \mathrm{~nm}$.

\subsection{DLS/SLS analysis}

The conformations of AAPs in dilute solution near the $\mathrm{pI}(\mathrm{pH}=4)$ were further analyzed by DLS/SLS. Table 2 shows that Poly (AA-co-DMAPMA) and Poly (AA-coMAPTAC) had smaller $R_{g}$ and $R_{h}$ than the others. Their $\rho$ 

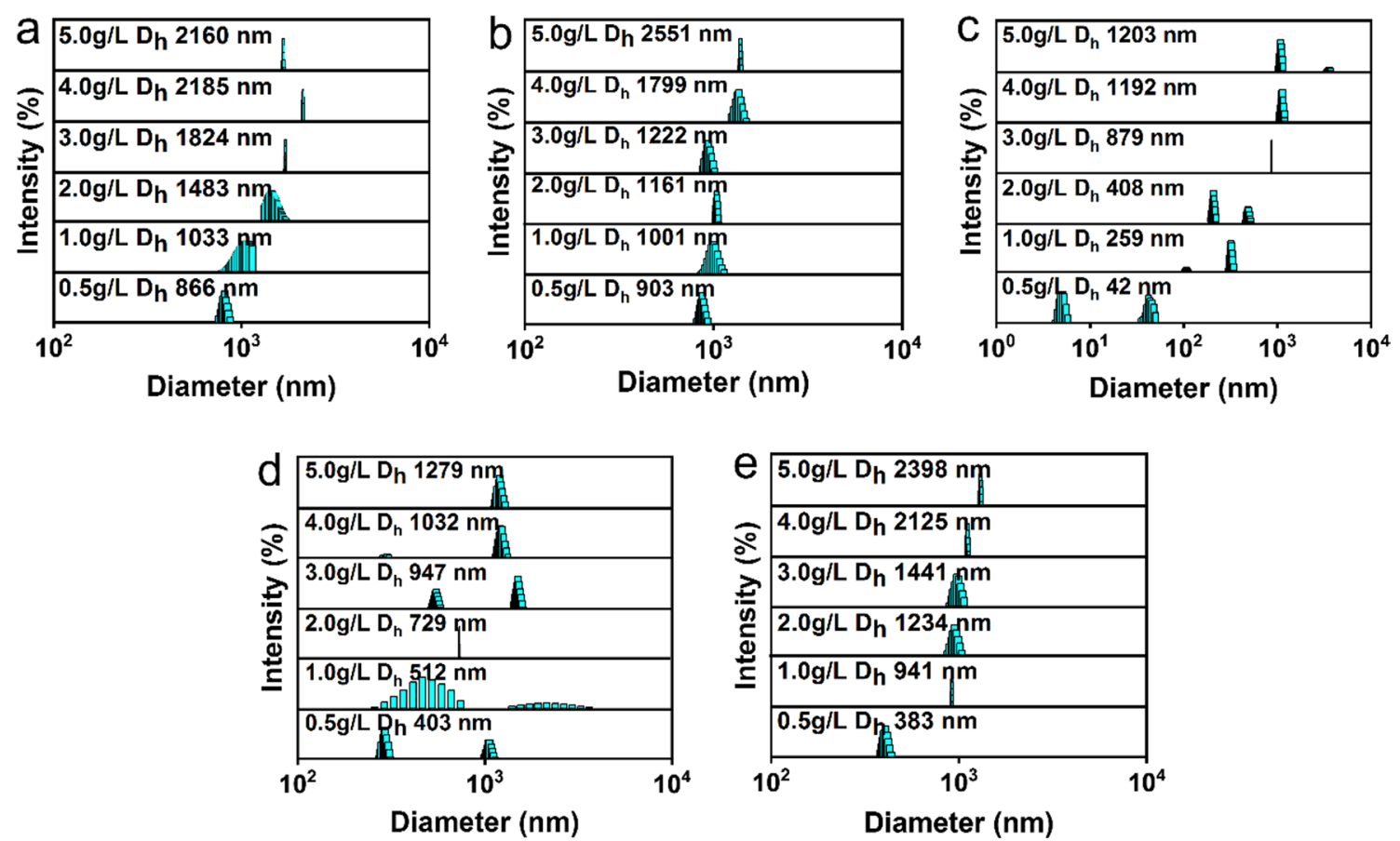

Fig. 3 Concentration dependence of the $D_{h}$ of Poly (AA-co-DAC) (a), Poly (AA-co-DMC) (b), Poly (AA-co-MAPTAC) (c), Poly (AA-co-DMAPMA) (d) and Poly (AA-Co-DMAEMA) (e) at pl

Table 2 Light Scattering Parameters of AAPS

\begin{tabular}{lrrll}
\hline Sample & $\mathbf{R}_{\mathbf{g}}(\mathbf{n m})$ & $\mathbf{R}_{\mathbf{h}}(\mathbf{n m})$ & $\mathbf{\rho}\left(\mathbf{R}_{\mathbf{g}} / \mathbf{R}_{\mathbf{h}}\right)$ & $\mathbf{A}_{\mathbf{2}}\left(\mathbf{m o l} \cdot \mathbf{d m}^{\mathbf{3}} / \mathbf{g}^{\mathbf{2}}\right)$ \\
\hline Poly (AA-co-DAC) & $241.8^{*}$ & 229.1 & 1.06 & - \\
Poly (AA-co-DMC) & $114.6^{*}$ & 122.4 & 0.94 & - \\
Poly (AA-co-MAPTAC) & 7.6 & 5.2 & 1.46 & $2.434 \mathrm{e}-06$ \\
Poly (AA-co-DMAPMA) & 14.8 & 7.9 & 1.87 & $1.413 \mathrm{e}-06$ \\
Poly (AA-co-DMAEMA) & 136.9 & 133.0 & 1.03 & $-1.211 \mathrm{e}-08$ \\
\hline
\end{tabular}

*Apparent radius of gyration

values $\left(R_{g} / R_{h}\right)$ were 1.87 and 1.46 , respectively, suggesting that they were in the shape of coiled linear flexible chains $[34,35]$. The other three AAPs showed $\rho$ values from 0.9 to 1.1 , indicating that they were in the shape of hollow spheres and exhibited a higher extent of aggregation [36, 37]. Poly (AA-co-DMC) and Poly (AA-co-DAC) showed more intense aggregation behavior and obvious concentration dependence under this condition. Thus, their $R_{g}$ and $A_{2}$ could not be obtained by Zimm plot extrapolation. $A_{2}$ was used to characterize the intensity of interactions between AAP chains in dilute solution. $\mathrm{A}_{2}$ of Poly (AA-co-DMAEMA) was negative, suggesting that electrostatic attraction was dominant between the polymer chains, and Poly (AA-co-DMAEMA) tended to aggregate near the $\mathrm{pI}(\mathrm{pH}=4)$. Conversely, $\mathrm{A}_{2}$ was positive for Poly
(AA-co-DMAPMA) and Poly (AA-co-MAPTAC), which meant that electrostatic repulsion was dominant between the polymer chains, and the polymer tended to dissolve near the $\mathrm{pI}[37,38]$. Therefore, light-scattering analysis also demonstrated that Poly (AA-co-DMAPMA)/Poly (AA-co-MAPTAC) containing amide in the cationic monomer showed smaller size and more dispersed and flexible state in aqueous solution near the pI compared with the other AAPs containing ester in the cationic monomers.

\subsection{DWS analysis}

DWS, a modern light scattering technique, can be used to investigate the microrheological properties of polymer solution and to characterize turbid samples [39]. DWS extends DLS to media with multiple scattering, treating the transport of light as a diffusion process. It collects the multiply scattered light from the sample into a correlator, and the intensity autocorrelation function $\left(\mathrm{g}^{2}(\mathrm{t})-1\right)$ can be determined to provide information about the local dynamics of particle dispersions [40].

The validity of the DWS is confirmed by the $\mathrm{L} / \mathrm{I}^{*}$, where $\mathrm{L}$ is the optical thickness of the cuvette, and $\mathrm{l}^{*}$ is the transport mean free path which represents the turbidity of sample. All DWS measurements were performed at $\mathrm{L} / 1^{*}>4$ [41]. Figure 4 shows the intensity autocorrelation function of the AAPs at the pI. The correlation function 


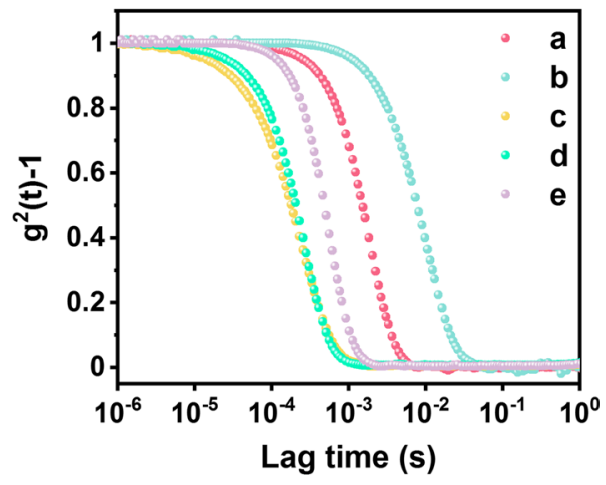

Fig. 4 Intensity autocorrelation function of Poly (AA-Co-DAC) (a), Poly (AA-co-DMC) (b), Poly (AA-co-MAPTAC) (c), Poly (AA-co-DMAPMA) (d) and Poly (AA-CO-DMAEMA) (e) at pl

of Poly (AA-co-DMC) decayed more slowly than the others. This fact demonstrated that Poly (AA-co-DMC) aggregated more heavily at the $\mathrm{pI}$, resulting in a slower diffusion of polymer molecules in solution [42]. The correlation functions of Poly (AA-co-MAPTAC) and Poly (AA-co-DMAPMA) decayed faster among the AAPs, implying that they were more stable in solution. The DWS results were consistent with those of $\mathrm{pH}$ dependence and concentration dependence the AAPs.

\subsection{Analysis on the charge-carrying ability of AAPs}

The aggregation state of a polymer in solution is influenced by its charge density and charge distribution. In this study, the anionic monomer of the five AAPs was acrylic acid, while the cationic monomers differed from one another. The cationic degrees of these AAPs from $\mathrm{pH} 2$ to 6 were determined to characterize the amount of cationic charge on the polymers $(\mathrm{mol} / \mathrm{g})$. When the $\mathrm{pH}$ was near the $\mathrm{pI}(\mathrm{pH}=\mathrm{pI}$ and $\mathrm{pH}=4)$, Poly $(\mathrm{AA}-\mathrm{co}-$ MAPTAC) and Poly (AA-co-DMAPMA) showed higher cationic degrees than the others (Fig. 5). Moreover,
Table 3 Zeta potentials of AAPs near the pl

\begin{tabular}{lrrrl}
\hline Sample & \multicolumn{3}{l}{ Zeta potential $(\mathbf{m V})$} & \\
\cline { 2 - 5 } & $\mathbf{p l}-\mathbf{0 . 5}$ & $\mathbf{p l}-\mathbf{0 . 3}$ & $\mathbf{p l}+\mathbf{0 . 3}$ & $\mathbf{p l}+\mathbf{0 . 5}$ \\
\hline Poly (AA-CO-DAC) & $8.1 \pm 0.9$ & $6.6 \pm 0.7$ & $-3.6 \pm 1.3$ & $-4.4 \pm 1.6$ \\
Poly (AA-CO-DMC) & $5.4 \pm 1.2$ & $2.0 \pm 1.4$ & $-4.9 \pm 0.5$ & $-6.0 \pm 2.3$ \\
Poly (AA-CO-MAPTAC) & $11.2 \pm 0.9$ & $9.9 \pm 1.1$ & $-6.5 \pm 1.3$ & $-10.0 \pm 1.7$ \\
Poly (AA-CO-DMAPMA) & $11.3 \pm 0.6$ & $9.7 \pm 0.3$ & $-4.7 \pm 1.1$ & $-8.4 \pm 1.4$ \\
Poly (AA-co-DMAEMA) & $4.6 \pm 0.4$ & $3.0 \pm 1.6$ & $-3.7 \pm 1.6$ & $-1.6 \pm 0.5$ \\
\hline
\end{tabular}

Table 4 Quantum chemical calculations of molecular models of AAPS

\begin{tabular}{lccccc}
\hline Molecular model & $\boldsymbol{\varepsilon}_{\mathrm{H}}(\mathrm{eV})$ & $\boldsymbol{\varepsilon}_{\mathrm{L}}(\mathrm{eV})$ & $\boldsymbol{\eta}(\mathrm{eV})$ & $\boldsymbol{\mu}(\mathrm{eV})$ & $\boldsymbol{\omega}(\mathrm{eV})$ \\
\hline Poly (AA-co-DAC) & -0.2804 & -0.0185 & 0.2619 & -0.1494 & 0.0426 \\
Poly (AA-Co-DMC) & -0.2805 & -0.0223 & 0.2582 & -0.1514 & 0.0444 \\
Poly (AA-co-MAPTAC) & -0.2671 & -0.0099 & 0.2572 & -0.1385 & 0.0373 \\
Poly (AA-co-DMAPMA) & -0.2243 & -0.0014 & 0.2229 & -0.1129 & 0.0286 \\
Poly (AA-co-DMAEMA) & -0.2183 & -0.0092 & 0.2091 & -0.1137 & 0.0309 \\
\hline
\end{tabular}

their zeta potentials were also higher in the $\mathrm{pH}$ range of $\mathrm{pI} \pm 0.5$ (Table 3 ). These data suggested that Poly (AAco-MAPTAC) and Poly (AA-co-DMAPMA) with amide in the cationic monomers could quickly carry more net charge when the $\mathrm{pH}$ climbed over the pI. Therefore, their intra-/inter-chain electrostatic repulsions were rapidly enhanced, which could effectively reduce the degree of aggregation. The results also coincided with the $\mathrm{pH}$ dependence and light scattering analysis.

The charge-carrying ability of AAPs was further evaluated by quantum chemical calculations. Lower value of electrophilic factor $\omega$ means stronger nucleophilicity and protons binding ability [43-45]. Table 4 shows that the molecular model of Poly (AA-co-MAPTAC) had the

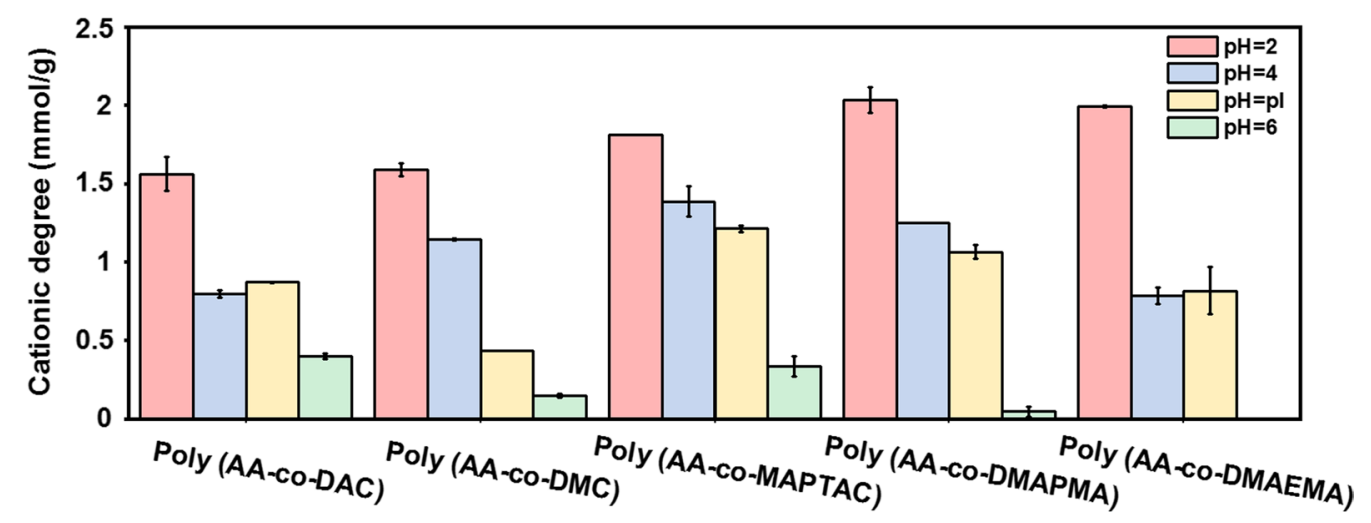

Fig. 5 The cationic degree of AAPs under different $\mathrm{pH}$ conditions 
lowest $\omega$ value of $0.0373 \mathrm{eV}$ among the AAPs with quaternary ammonium groups. For the AAPs with tertiary amine groups, the $\omega$ value of the molecular model of Poly (AA-Co-DMAPMA) was lower than that of Poly (AA-coDMAEMA). These results indicated that Poly (AA-coMAPTAC) and Poly (AA-co-DMAPMA) were easier to bind protons and carry positive charges than the other AAPs, which was consistent with the results in Fig. 5. This should be attributed to the fact that the amide in these two cationic monomers had a stronger electron supplying ability than the ester in the cationic monomers of the other AAPs, and therefore, are convenient in application.

\section{Conclusions}

Five linear AAPs with similar molecular weights were synthesized using acrylic acid and different cationic monomers. The aggregation of all the AAPs in aqueous solution showed $\mathrm{pH}$ and concentration dependence. However, their aggregation behavior was significantly different near the pI. Poly (AA-co-MAPTAC) and Poly (AA-co-DMAPMA) were in the shape of random coils with smaller particle size, while the other AAPs exhibited a hollow spherical shape with more severe aggregation. The reason should be that the amide groups in the cationic monomers (MAPTAC and DMAPMA) enhanced the nucleophilicity of the AAPs, and the corresponding AAPs obtained more positive charges and generated stronger electrostatic repulsion when the $\mathrm{pH}$ dropped just below the pI. The results above provide guidance for the design and synthesis of novel amphoteric polymer retanning agent that can maintain a stable solution state over a wide $\mathrm{pH}$ range, and therefore, are convenient in application.

\begin{abstract}
Abbreviations
AAP: Amphoteric acrylic polymer; pl: Isoelectric point; AA: Acrylic acid; DAC: Acryloyloxyethyl trimethyl ammonium chloride; DMC: Methacryloxyethyl trimethyl ammonium chloride; MAPTAC: 3-(Methacryloylaminopropyl) trimethylammonium chloride; DMAEMA: Dimethylaminoethyl methacrylate; DMAPMA: Dimethylaminopropyl methacrylamide; Poly (AA-co-DAC): Copolymer of AA and DAC; Poly (AA-Co-DMC): Copolymer of AA and DMC; Poly (AA-Co-MAPTAC): Copolymer of AA and MAPTAC; Poly (AA-CO-DMAPMA): Copolymer of AA and DMAPMA; Poly (AA-CO-DMAEMA): Copolymer of AA and DMAEMA; DLS/ SLS: Dynamic and static light scattering; DWS: Diffusing wave spectroscopy.
\end{abstract}

\section{Supplementary Information}

The online version contains supplementary material available at https://doi. org/10.1186/s42825-022-00078-3.

Additional file 1. Fig. S1. FT-IR spectra of Poly (AA-co-DAC) (a), Poly (AAco-DMC) (b), Poly (AA-co-MAPTAC) (c), Poly (AA-co-DMAPMA) (d) and Poly (AA-Co-DMAEMA) (e). Fig. S2. ${ }^{13} \mathrm{C}-\mathrm{NMR}$ spectra of Poly (AA-CO-DAC) (A), Poly (AA-Co-DMC) (B), Poly (AA-co-MAPTAC) (C), Poly (AA-co-DMAPMA) (D) and Poly (AA-CO-DMAEMA) (E).

\section{Acknowledgements}

We thank Dr. Bin Liu from Nanjing Tech University and Dr. Pengfei Sun from Nanjing University of Posts and Telecommunications for guiding DLS/SLS measurements, and thank Prof. Wenhua Zhang from National Engineering Laboratory for Clean Technology of Leather Manufacture, Sichuan University for guiding quantum chemical calculations.

\section{Authors' contributions}

$Q L, J L$, and $Y W$ conceived the idea. QL performed the experiments and drafted the manuscript. YY participated in part of the experiments. YW and $\mathrm{BS}$ analyzed the results and revised the manuscript. All authors read and approved the final manuscript.

\section{Funding}

This work was financially supported by the Tianfu Ten-thousand Talents Program of Sichuan Province and the National Key R\&D Program (2017YFB0308500).

\section{Availability of data and materials}

All data from this study are presented in the paper and the additional file.

\section{Declarations}

\section{Competing interests}

The authors declare that they have no competing interests.

\section{Author details}

${ }^{1}$ Key Laboratory of Leather Chemistry and Engineering (Sichuan University), Ministry of Education, Chengdu 610065, China. ${ }^{2}$ National Engineering Laboratory for Clean Technology of Leather Manufacture, Sichuan University, Chengdu 610065, China. ${ }^{3}$ Sichuan Tingjiang New Material, Inc., Shifang 618412, China.

Received: 8 November 2021 Accepted: 20 January 2022

Published online: 15 February 2022

\section{References}

1. Yu Y, Lin YR, Zeng YH, Wang YN, Zhang WH, Zhou JF, et al. Life cycle assessment for chrome tanning, chrome-free metal tanning, and metalfree tanning systems. ACS Sustain Chem Eng. 2021;9(19):6720-31. https:// doi.org/10.1021/acssuschemeng.1c00753.

2. Wang YN, Shi B. Progress of key clean technologies in leather industry. Chem Ind Eng Prog. 2016;35(6):1865-74. https://doi.org/10.16085/j.issn. 1000-6613.2016.06.028.

3. Hedberg YS. Chromium and leather: a review on the chemistry of relevance for allergic contact dermatitis to chromium. J Leath Sci Eng. 2020;2(1):1-15. https://doi.org/10.1186/s42825-020-00027-y.

4. Yu Y, Wang YN, Ding W, Zhou JF, Shi B. Preparation of highly-oxidized starch using hydrogen peroxide and its application as a novel ligand for zirconium tanning of leather. Carbohyd Polym. 2017;174:823-9. https:// doi.org/10.1016/j.carbpol.2017.06.114.

5. Guo XR, Yu Y, Wang YN, Shi B. Oxidized maltodextrin: a novel ligand for aluminum-Zirconium complex tanning. J Am Leather Chem As. 2021;116(5):15561. https://doi.org/10.34314/jalca.v116i5.4293.

6. Wang YN, Huang WL, Zhang HS, Tian L, Zhou JF, Shi B. Surface charge and isoelectric point of leather-a novel determination method and its application in leather making. J Am Leather Chem As. 2017;112(7):224-31.

7. Song Y, Wang YN, Zeng YH, Wu HP, Shi B. Quantitative determinations of isoelectric point of retanned leather and distribution of retanning agent. J Am Leather Chem As. 2018;113(7):232-8.

8. Huang WL, Song Y, Yu Y, Wang YN, Shi B. Interaction between retanning agents and wet white tanned by a novel bimetal complex tanning agent. J Leath Sci Eng. 2020;2(1):1-9. https://doi.org/10.1186/s42825-020-00023-2.

9. Wang XC, Wang WN, Liu XH, Wang YY. Amphoteric functional polymers for leather wet finishing auxiliaries: a review. Polym Advan Technol. 2021;32(5):1951-64. https://doi.org/10.1002/pat.5248. 
10. Wang XC, Sun SW, Zhu X, Guo PY, Liu XH, Liu CL, Lei M. Application of amphoteric polymers in the process of leather post-tanning. J Leath Sci Eng. 2021;3(1):1-9. https://doi.org/10.1186/s42825-021-00050-7.

11. Hao DY, Wang XC, Liu XH, Zhu X, Sun SW, Li J, Yue OY. A novel eco-friendly imidazole ionic liquids based amphoteric polymers forhigh performance fatliquoring in chromium-free tanned leather production. J Hazard Mater. 2020;399:123048. https://doi.org/10.1016/j.jhazmat.2020.123048.

12. Ma JZ, Liu QW, Wu MX, Tian ZH. Preparation and assistant-dyeing of formaldehyde-free amphoteric acrylic retanning agent. J Leath Sci Eng. 2021;3(1):1-13. https://doi.org/10.1186/s42825-021-00066-Z.

13. Wang XC, Hao DY, Chai XY, Li J. Effect of an amphoteric chromium-free polymer retanning agent with reactive aldehyde groups on collagen fibers. J Am Leather Chem As. 2019;114(10):373-81.

14. Xu W, Chai XY, Zhao GH, Li J, Wang XC. Preparation of reactive amphoteric polyurethane with multialdehyde groups and its use as a retanning agent for chrome-free tanned leather. J Appl Polym Sci. 2019;136(37):47940. https://doi. org/10.1002/app.47940.

15. Wang XC, Yan Z, Liu XH, Qiang TT, Chen LA, Guo PY, Yue OY. An environmental polyurethane retanning agent with the function of reducing free formaldehyde in leather. J Clean Prod. 2019;207:679-88. https://doi.org/10.1016/j.jclep ro.2018.10.056.

16. Xu W, Yang R, Chai XY, Qiang XH, Wang XC, Zhao T. Preparation and appliaction of amphoteric phenolic synthetic tanning agent. China Leather. 2021;50(6):19-24. https://doi.org/10.13536/j.cnki.issn1001-6813.2021-006-004

17. Gohy JF, Creutz S, Garcia M, Mahltig B, Stamm M, Jerome R. Aggregates formed by amphoteric diblock copolymers in water. Macromolecules. 2000;33(17):6378-87. https://doi.org/10.1021/ma992016j.

18. Song J, Yamagushi T, Silva DJ, Hubbe MA, Rojas OJ. Effect of charge asymmetry on adsorption and phase separation of polyampholytes on silica and cellulose surfaces. J Phys Chem B. 2010;114(2):719-27. https://doi.org/10.1021/jp909 $047 \mathrm{t}$

19. Rabiee A, Ershad-Langroudi A, Jamshidi H. Polyacrylamide-based polyamphoIytes and their applications. Rev Chem Eng. 2014;30(5):501-19. https://doi.org/ 10.1515/revce-2014-0004.

20. Higgs PG, Joanny JF. Theory of polyampholyte solutions. J Chem Phys. 1991;94(2):1543-54

21. Chen FS, Xie LS, Wei DJ, Chen XY. Determination of the charge of polymers by colloidal titration. China Pap. 2000;2:30-4

22. Plank J, Sachsenhauser B. Experimental determination of the effective anionic charge density of polycarboxylate superplasticizers in cement pore solution. Cem Concr Res. 2009;39(1):1-5. https://doi.org/10.1016/j.cemconres.2008.09. 001.

23. Das I, Borah JH, Sarma D, Hazarika S. Synthesis of PAMAM dendrimer and its derivative PAMOL: determination of thermophysical properties by DFT. J Macromol Sci A. 2018;55(7):544-51. https://doi.org/10.1080/10601325.2018. 1481345.

24. Esmkhani R, Monajjemi M. Electronic structural investigation of boron nitride nano cage $\left(\mathrm{B}_{30} \mathrm{~N}_{20}\right)$ in point of exchange and correlation energy. J Comput Theor Nanos. 2015;12(4):652-9. https://doi.org/10.1166/jctn.2015.3782.

25. Zhang YK, Yang W. Perspective on "Density-functional theory for fractional particle number: derivative discontinuities of the energy."Theor Chem Acc. 2000;103:346-8. https://doi.org/10.1007/978-3-662-10421-7_57.

26. Chen Y, Feng L, Liu BZ, Peng JL, Chen Y, Xu CA, Ren J. Study of microwavetemplate initiated copolymerization peculiarity and evaluation on the coal floc distinctive behavior and flocculation performance. J Appl Polym Sci. 2020;137(46):49519. https://doi.org/10.1002/app.49519.

27. Harn YW, He YJ, Wang ZW, Chen YH, Liang S, Li ZL, Li Q, Zhu L, Lin ZQ. Synthesis of amphiphilic and double hydrophilic star-like block copolymers and the dual $\mathrm{pH}$-responsiveness of unimolecular micelle. Macromolecules. 2020;53(19):8286-95. https://doi.org/10.1021/acs.macromol.0c00918.

28. Yang J, Li J, Tang BT, Zhang SF. Solution properties of amphoteric macromolecular dyes derived from poly (acrylamide-co-vinylamine). J Polym Res. 2015;22(2):1-8. https://doi.org/10.1007/s10965-015-0659-9.

29. Dong AJ, Hou GL, Wang YX, Sun DX. Properties of amphoteric polyurethane waterborne dispersions. I. Dependence on $\mathrm{pH}$ value in salt-free media. J Polym Sci Pol Phys. 2002;40(10):972-9. https://doi.org/10.1002/polb.10153.

30. Kamiyama Y, Israelachvili J. Effect of $\mathrm{pH}$ and salt on the adsorption and interactions of an amphoteric polyelectrolyte. Macromolecules. 1992;25(19):5081-8. https://doi.org/10.1021/ma00045a039.

31. Xu SM, Wu RL, Huang XJ, Gao LQ, Wang JD. Effect of the anionic-group/ cationic-group ratio on the swelling behavior and controlled release of agrochemicals of the amphoteric, superabsorbent polymer poly (acrylic acidco-diallyldimethylammonium chloride). J Appl Polym Sci. 2006;102(2):986-91. https://doi.org/10.1002/app.23990.

32. Armentrout RS, McCormick CL. Water-soluble polymers. 77. Amphoteric cyclocopolymers with sulfobetaine units: Phase behavior in aqueous media and solubilization of p-cresol in microdomains. Macromolecules. 2000;33(8):294451. https://doi.org/10.1021/ma991531e.

33. Mincheva R, Bougard F, Paneva D, Vachaudez M, Manolova N, Dubois P, Rashkov I. Self-assembly of N-carboxyethylchitosan near the isoelectric point. J Polym Sci Pol Chem. 2008;46(20):6712-21. https://doi.org/10.1002/pola.22978.

34. Sletmoen M, Geissler E, Stokke BT. Determination of molecular parameters of linear and circular scleroglucan coexisting in ternary mixtures using light scattering. Biomacromol. 2006;7(3):858-65. https://doi.org/10.1021/bm050990m.

35. Li LW, He C, He WD, Wu C. Formation kinetics and scaling of "defect-free" hyperbranched polystyrene chains with uniform subchains prepared from seesaw-type macromonomers. Macromolecules. 2011:44(20):8195-206. https://doi.org/10.1021/ma201687s.

36. Xie $D$, Jiang $M$, Zhang GZ, Chen DY. Hydrogen-bonded dendronized polymers and their self-assembly in solution. Chem Eur J. 2007;13(12):3346-53. https:// doi.org/10.1002/chem.200601361.

37. Gasilova ER, Lapina IM, Kulminskaya AA, Skorik YA. Branched architecture of fucoidan characterized by dynamic and static light scattering. Colloid Polym Sci. 2020;298(10):1349-59. https://doi.org/10.1007/s00396-020-04706-4.

38. Maia AMS, Costa M, Borsali R, Garcia RB. Rheological behavior and scattering studies of acrylamide-based copolymer solutions. Macomol Symp. 2005;229(1):217-27. https://doi.org/10.1002/masy.200551127.

39. Xu JY, Boddu VM, Liu SX, Liu WC. A comparative study of microrheology of nanocellulose produced from corn stover using diffusing wave spectroscopy (DWS) and mechanical rheometry. Cell Chem Technol. 2020;54(1-2):27-32. https://doi.org/10.35812/CelluloseChemTechnol.2020.54.03.

40. Scheffold F. Particle sizing with diffusing wave spectroscopy. J Disper Sci Technol. 2002;23(5):591-9. https://doi.org/10.1081/DIS-120015365.

41. Niu F, Ahmad M, Fan JM, Ritzoulis C, Chen JS, Luo ZS, Pan WC. The application of diffusing wave spectroscopy (DWS) in soft foods. Food Hydrocolloids. 2019;96:671-80. https://doi.org/10.1016/j.foodhyd.2019.06.011.

42. Xu JY, Inglett GE, Liu SX, Boddu VM. Micro-heterogeneity and micro-rheological properties of high-viscosity barley $\beta$-glucan solutions studied by diffusing wave spectroscopy (DWS). Food Biophys. 2016;11(4):339-44. https://doi.org/ 10.1007/s11483-016-9447-2.

43. Parr RG, Szentpály L, Liu S. Electrophilicity index. J Am Chem Soc. 1999;121(9):1922-4. https://doi.org/10.1021/ja983494x.

44. Ayers PW, Parr RG, Pearson RG. Elucidating the hard/soft acid/base principle: a perspective based on half-reactions. J Chem Phys. 2006;124(19): 194107. https://doi.org/10.1063/1.2196882.

45. Pérez P. Global and local electrophilicity patterns of diazonium ions and their reactivity toward $\pi$-nucleophiles. J Org Chem. 2003;68(15):5886-9. https://doi.org/10.1021/jo030125x.

\section{Publisher's Note}

Springer Nature remains neutral with regard to jurisdictional claims in published maps and institutional affiliations. 